\title{
Protecting vaccine programs and the public
}

I n I986, this journal published an article by the Canadian Pediatric Society calling for Canada to develop a no-fault compensation program for vaccination injuries. ${ }^{1}$ More than 2 decades later there is no such national system in place, despite repeated calls for its introduction. However, recent developments, including the possible need to administer to millions of Canadians an incompletely tested pandemic influenza vaccine and the rapid increase in recommended pediatric vaccines, make the creation of a no-fault program a national priority.

The fundamental premise behind a no-fault compensation system is that people receive immunization not only for their own benefit but also for the benefit of the community. Therefore if, in the process of contributing to this public good, an individual should be harmed, there is a strong ethical argument that they should be compensated. This compensation process should bypass the legal system, which is not well suited to addressing these injuries. Justice Horace Krever's landmark report on the tainted blood tragedy called for a nofault compensation system for those infected by contaminated blood products, arguing that such people, already harmed once, should not have to endure the legal process to seek redress.

In the I980s, the United States introduced no-fault compensation for 2 reasons apart from the ethical and socialjustice arguments. First, a crisis in public confidence in vaccination resulted in decreasing coverage rates. Second, hundreds of lawsuits against vaccine manufacturers were rapidly crippling the industry. Many manufacturers ceased producing vaccines, which created supply shortages, increased vaccine costs and discouraged innovation. ${ }^{2}$ The US no-fault system requires that individuals demonstrate that an acknowledged adverse reaction occurred within a specified period after vaccination. Compensation is then based on predetermined amounts depending on the extent of injury. In retrospect, the introduction of the no-fault program has been viewed as a success and credited with, in part, re-establishing public confidence in vaccines and providing a secure environment for vaccine manufacturers - while also providing compensation for those who have been injured.

In Canada, at present, we have no such crisis of confidence in vaccines, nor the same levels of concern about legal actions against our vaccine suppliers. Nevertheless, important points of concern are emerging. Perhaps most urgently, the necessarily rapid roll-out of vaccines in the event of pandemic influenza means that people will inevitably be exposed to vaccines for which there will be too little time for a complete determination of safety. Manufacturers may be uncomfortable releasing such vaccines in the absence of protection from liability, and some people may be uncomfortable receiving an incom- pletely tested vaccine, either of which would undermine efforts to control the pandemic. A no-fault compensation program could address both of these concerns by legally protecting manufacturers and addressing the concerns of vaccine recipients. Second, public acceptance of the increasing numbers of recommended childhood vaccines may eventually reach its limits. A no-fault compensation program could help sustain public support for vaccines as these programs continue to expand, by demonstrating public health's commitment to vaccine recipients. Third, with more vaccines being introduced, there is an increased likelihood of the emergence of a rare adverse event not identified in clinical trials. The existence of a compensation program could provide for the individuals harmed, helping to maintain the public's trust if and when such episodes occur.

No-fault compensation programs exist in at least $\mathrm{I} 3$ jurisdictions, including the United States and the province of Quebec. $^{3}$ The programs have been shown to be both feasible and cost-effective. Parliament could probably pass a law creating the program without much controversy. How much would be paid in case of injury and how the system is paid for are, of course, hugely important details, but we would have the benefit of learning from other countries' experiences.

We should not wait for the factors that triggered the US adoption of no-fault compensation to emerge in Canada before instituting such a program. Once public confidence is lost, it is difficult to regain - and our vaccine programs are too important to the protection of our population's health to take this risk. Most importantly, Canada should institute no-fault compensation, because it is the just and ethical way to provide for the very rare individual who has been harmed by a vaccine.

\section{Kumanan Wilson \\ Associate Professor \\ Department of Medicine \\ University of Toronto \\ Toronto, Ont. \\ For the Editorial-Writing Team (Paul C. Hébert, Matthew Stanbrook, Barbara Sibbald, Ken Flegel, Noni McDonald and Amir Attaran)}

Competing interests: None declared.

\section{REFERENCES}

I. Canadian Pediatric Society. In support of a compensation plan for vaccineassociated injuries. CMAJ ז986;135:747-9.

2. Evans G. Update on vaccine liability in the United States: presentation at the $\mathrm{Na}$ tional Vaccine Program Office Workshop on strengthening the supply of routinely recommended vaccines in the United States, I2 February 2002. Clin Infect Dis 2006;42(Suppl 3):Sizo-7.

3. Evans G. Vaccine injury compensation programs worldwide. Vaccine 1999;17 (Suppl 3):S25-35. 